\title{
Dithiocarbamate residues in fruits, vegetables and herbs from the area of the south-eastern Poland in 2011-2013
}

\section{Pozostałości ditiokarbaminianów w owocach, warzywach i ziołach z terenu południowo-wschodniej Polski w latach 2011-2013}

\author{
Magdalena Podbielska, Ewa Szpyrka, Aneta Matyaszek, Anna Kurdziel, \\ Julian Rupar, Magdalena Słowik-Borowiec
}

Summary

In 2011-2013 in the Laboratory of Pesticide Residue Analysis of Plant Protection Institute - National Research Institute in Rzeszów 339 samples of fruits, vegetables and herbs were tested for the presence of dithiocarbamate fungicide residues. Dithiocarbamates were found in $27(8.0 \%)$ analysed samples. No exceeding of Maximum Residue Levels (MRLs) was stated. Dithiocarbamates were detected most frequently in: gooseberries $(45.4 \%$ of the samples of the crop), red currants (33.3\%), black currants (29.6\%), pears (18.7\%) and peaches (14.3\%).

Key words: dithiocarbamate residues; fruits; vegetables; fungicide; MRL

\section{Streszczenie}

W latach 2011-2013 w Laboratorium Badania Pozostałości Środków Ochrony Roślin Terenowej Stacji Doświadczalnej Instytutu Ochrony Roślin - Państwowego Instytutu Badawczego w Rzeszowie przebadano 339 próbek owoców, warzyw oraz upraw zielarskich na obecność pozostałości fungicydów ditiokarbaminianowych. W 27 (8,0\%) badanych próbkach wykryto pozostałości ditiokarbaminianów. W żadnej z próbek nie stwierdzono przekroczenia najwyższych dopuszczalnych poziomów pozostałości (NDP). Ditiokarbaminiany wykrywano najczęściej w: agreście (45,4\% badanych próbek tej uprawy), porzeczkach czerwonych (33,3\%), porzeczkach czarnych (29,6\%), gruszkach (18,7\%) i brzoskwiniach (14,3\%).

Słowa kluczowe: pozostałości ditiokarbaminianów; owoce; warzywa; fungicydy; NDP

Instytut Ochrony Roślin - Państwowy Instytut Badawczy

Terenowa Stacja Doświadczalna

Langiewicza 28, 35-101 Rzeszów

M.Podbielska@iorpib.poznan.pl 


\section{Wstęp / Introduction}

Wykorzystywanie chemicznych środków ochrony roślin jest obecnie najbardziej efektywnym sposobem ochrony upraw przed agrofagami. Stosowanie tych substancji wiąże się jednak z ryzykiem wystąpienia ich pozostałości w uprawach, co ma wpływ na zdrowie ludzi poprzez zanieczyszczenie żywności. W celu uniknięcia wprowadzania do obrotu płodów rolnych stwarzających zagrożenie dla zdrowia człowieka, prowadzone są urzędowe badania kontrolne, będące bardzo ważnym elementem ochrony przed ujemnymi skutkami stosowania środków ochrony roślin (ś.o.r). W polskim rolnictwie jedną z najważniejszych grup fungicydów stosowanych do ochrony roślin są ditiokarbaminiany (DTC). Wśród fungicydów ditiokarbaminowych wyróżnia się: etylenobis-ditiokarbaminiany (maneb, zineb, mankozeb, metiram, propineb), N,N-dimetyloditiokarbaminiany (ziram) oraz disiarczki (tiuram). Niektóre $\mathrm{z}$ tych związków wprowadzono do praktyki rolniczej już w latach 30. ubiegłego stulecia (Różański 1992). Charakteryzują się szerokim spektrum stosowania i niewielką toksycznością ostrą dla ssaków, jednak pewne ich metabolity, a zwłaszcza etylenotiomocznik (ETU), wykazują właściwości rakotwórcze i teratogenne, blokują grupy tiolowe enzymów i białek, hamują aktywność enzymów i tyroksyny, a także mogą powodować miejscowe podrażnienia i reakcje uczuleniowe (Różański 1992; WHO 1994; EPA 2001; Belpoggi 2002).

Monitoring pozostałości chemicznych ś.o.r w żywności pochodzenia roślinnego pozwala na sprawdzenie prawidłowości ich stosowania oraz na kontrolę stężeń pozostałości w odniesieniu do najwyższych dopuszczalnych poziomów pozostałości (NDP) obowiązujących w Polsce.

Celem pracy jest przedstawienie wyników badań pozostałości DTC w próbkach świeżych owoców, warzyw oraz ziół pobranych w latach 2011-2013 z terenu południowo-wschodniej Polski.

\section{Materiały i metody / Materials and methods}

Materiał do badań stanowiło 339 próbek pochodzących z terenu południowo-wschodniej Polski. Kontrola występowania pozostałości DTC prowadzona była w latach 2011-2013. Badaniami objęto 25 upraw - 12 owoców, 10 warzyw oraz 3 uprawy ziół. Uprawy: buraka ćwikłowego, marchwi, pietruszki oraz selera wprowadzono do badań monitoringowych od 2013 roku. Analizy wykonywane były w ramach urzędowej kontroli zlecanej przez Ministerstwo Rolnictwa i Rozwoju Wsi oraz na zlecenie producentów i firm zajmujących się przetwórstwem, skupem i eksportem warzyw.

Próbki do badań w ramach urzędowej kontroli pobierane były zgodnie $\mathrm{z}$ harmonogramem, przez pracowników Państwowej Inspekcji Ochrony Roślin i Nasiennictwa, W sposób losowy z miejsc produkcji rolniczej (Rozporządzenie 2007), na obszarze południowo-wschodniej Polski. W przypadku indywidualnych zleceń, próbki dostarczane były przez producentów.
Pozostałości ditiokarbaminianów oznaczano akredytowaną według normy PN-EN ISO/IEC 17025 (2005) metodą spektrofotometryczną (Chmiel 1979; Sadło i wsp. 2003), zgodnie z wymaganiami Komisji Europejskiej (Document SANCO 2011). Absorbancję produktów reakcji mierzono przy długości fali $662 \mathrm{~nm}$. Stężenie DTC obliczano i wyrażano w miligramach disiarczku węgla na kilogram badanego produktu. Granica oznaczalności (GO) wynosiła $0,05 \mathrm{mg} / \mathrm{kg}$. Uzyskane wyniki porównywano z NDP obowiązującymi w Polsce (Rozporządzenie 2005).

\section{Wyniki i dyskusja / Results and discussion}

W 27 badanych próbkach, co stanowiło 8,0\% wszystkich analizowanych próbek stwierdzono obecność pozostałości DTC. Dane dotyczące występowania pozostałości w poszczególnych latach przedstawione zostały na rysunku 1.

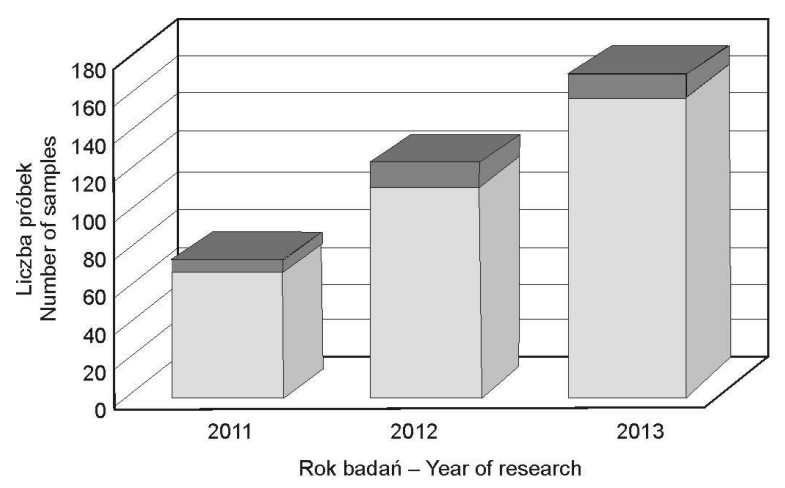

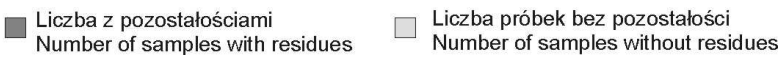

Rys. 1. Występowanie pozostałości ditiokarbaminianów w poszczególnych latach 2011-2013

Fig. 1. The occurrence of dithiocarbamate residues in individual years 2011-2013

Najczęściej DTC wykrywano w owocach. W warzywach stwierdzono tylko jedną pozostałość w uprawie pomidora spod osłon. Nie odnotowano pozostałości w uprawach zielarskich. Pozostałości DTC wykrywano najczęściej w: agreście (45,4\% badanych próbek tej uprawy), porzeczkach czerwonych $(33,3 \%)$, porzeczkach czarnych $(29,6 \%)$, gruszkach $(18,7 \%)$ i brzoskwiniach $(14,3 \%)$. W pozostałych uprawach częstotliwość występowania pozostałości nie przekraczała $10 \%$. Wyniki przedstawiono na rysunku 2.

W żadnej z badanych próbek nie stwierdzono pozostałości przekraczającej wartości NDP. Należy jednak podkreślić, że NDP dla DTC jest dużo wyższe w porównaniu do innych substancji czynnych (Rozporządzenie 2005). Szczegółowe dane o poziomach wykrytych pozostałości zamieszczono w tabeli 1.

W celu porównania stopnia zanieczyszczeń pestycydami owoców i warzyw z południowo-wschodniej Polski, najbardziej miarodajnym wydaje się odniesienie wyników badań do monitoringu krajowego. Analizy wykonywano w laboratoriach o podobnych możliwościach 


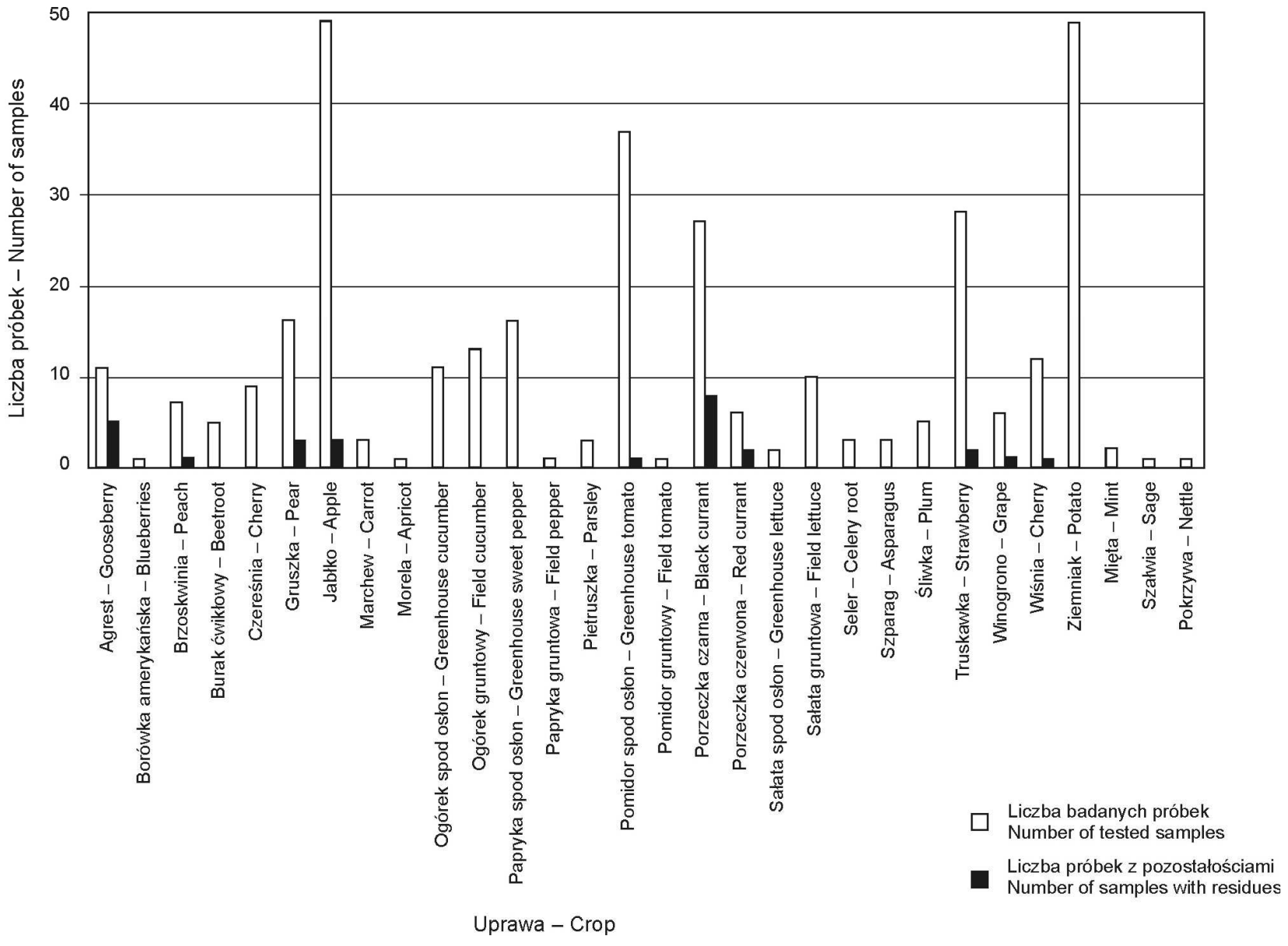

Rys. 2. Częstotliwość występowania pozostałości ditiokarbaminianów w latach 2011-2013

Fig. 2. Frequency of occurrence of dithiocarbamate residues in 2011-2013

Tabela 1. Pozostałości ditiokarbaminianów w badanych uprawach w latach 2011-2013

Table 1. Dithiocarbamate residues in analysed crops 201-2013

\begin{tabular}{|c|c|c|c|c|}
\hline $\begin{array}{l}\text { Uprawa } \\
\text { Crop }\end{array}$ & $\begin{array}{c}\text { Liczba } \\
\text { analizowanych } \\
\text { próbek } \\
\text { Number } \\
\text { of analysed } \\
\text { samples }\end{array}$ & $\begin{array}{c}\text { Liczba } \\
\text { pozostałości } \\
\text { w uprawie } \\
\text { Number } \\
\text { of residues } \\
\text { in crop }\end{array}$ & $\begin{array}{c}\text { Pozostałości ditiokarbaminianów } \\
\text { Dithiocarbamate residues } \\
{[\mathrm{mg} / \mathrm{kg}]}\end{array}$ & $\begin{array}{c}\mathrm{NDP} \\
\mathrm{MRL} \\
{[\mathrm{mg} / \mathrm{kg}]}\end{array}$ \\
\hline 1 & 2 & 3 & 4 & 5 \\
\hline $\begin{array}{l}\text { Agrest } \\
\text { Gooseberry }\end{array}$ & 11 & 5 & 0,$17 ; 0,32 ; 0,54 ; 0,66 ; 1,55$ & 5 \\
\hline $\begin{array}{l}\text { Borówka amerykańska } \\
\text { Blueberries }\end{array}$ & 1 & 0 & $<\mathrm{GO}(\mathrm{LOQ})$ & 5 \\
\hline $\begin{array}{l}\text { Brzoskwinia } \\
\text { Peach }\end{array}$ & 7 & 1 & 0,35 & 2 \\
\hline $\begin{array}{l}\text { Burak ćwikłowy } \\
\text { Beetroot }\end{array}$ & 5 & 0 & $<\mathrm{GO}$ & 0,5 \\
\hline $\begin{array}{l}\text { Czereśnia } \\
\text { Cherry }\end{array}$ & 9 & 0 & $<\mathrm{GO}$ & 2 \\
\hline $\begin{array}{l}\text { Gruszka } \\
\text { Pear }\end{array}$ & 16 & 3 & 0,$05 ; 0,39 ; 0,58$ & 5 \\
\hline $\begin{array}{l}\text { Jabłko } \\
\text { Apple }\end{array}$ & 49 & 3 & 0,$09 ; 0,87 ; 1,00$ & 5 \\
\hline $\begin{array}{l}\text { Marchew } \\
\text { Carrot }\end{array}$ & 3 & 0 & $<\mathrm{GO}$ & 0,2 \\
\hline
\end{tabular}




\begin{tabular}{|c|c|c|c|c|}
\hline 1 & 2 & 3 & 4 & 5 \\
\hline $\begin{array}{l}\text { Mięta } \\
\text { Mint }\end{array}$ & 2 & 0 & $<\mathrm{GO}$ & 5 \\
\hline $\begin{array}{l}\text { Morela } \\
\text { Apricot }\end{array}$ & 1 & 0 & $<\mathrm{GO}$ & 2 \\
\hline $\begin{array}{l}\text { Ogórek spod osłon } \\
\text { Greenhouse } \\
\text { cucumber }\end{array}$ & 11 & 0 & $<\mathrm{GO}$ & 2 \\
\hline $\begin{array}{l}\text { Ogórek gruntowy } \\
\text { Field cucumber }\end{array}$ & 13 & 0 & $<\mathrm{GO}$ & 2 \\
\hline $\begin{array}{l}\text { Papryka spod osłon } \\
\text { Greenhouse sweet } \\
\text { pepper }\end{array}$ & 16 & 0 & $<\mathrm{GO}$ & 5 \\
\hline $\begin{array}{l}\text { Papryka gruntowa } \\
\text { Field pepper }\end{array}$ & 1 & 0 & $<\mathrm{GO}$ & 5 \\
\hline $\begin{array}{l}\text { Pietruszka } \\
\text { Parsley }\end{array}$ & 3 & 0 & $<\mathrm{GO}$ & 0,2 \\
\hline $\begin{array}{l}\text { Pokrzywa } \\
\text { Nettle }\end{array}$ & 1 & 0 & $<\mathrm{GO}$ & 5 \\
\hline $\begin{array}{l}\text { Pomidor spod osłon } \\
\text { Greenhouse tomato }\end{array}$ & 37 & 1 & 0,15 & 3 \\
\hline $\begin{array}{l}\text { Pomidor gruntowy } \\
\text { Field tomato }\end{array}$ & 1 & 0 & $<\mathrm{GO}$ & 3 \\
\hline $\begin{array}{l}\text { Porzeczka czarna } \\
\text { Black currant }\end{array}$ & 27 & 8 & 0,$16 ; 0,27 ; 0,27 ; 0,60 ; 0,62 ; 0,89 ; 0,94 ; 1,8$ & 5 \\
\hline $\begin{array}{l}\text { Porzeczka czerwona } \\
\text { Red currant }\end{array}$ & 6 & 2 & 0,$52 ; 1,22$ & 5 \\
\hline $\begin{array}{l}\text { Sałata spod osłon } \\
\text { Greenhouse lettuce }\end{array}$ & 2 & 0 & $<\mathrm{GO}$ & 5 \\
\hline $\begin{array}{l}\text { Sałata gruntowa } \\
\text { Field lettuce }\end{array}$ & 10 & 0 & $<\mathrm{GO}$ & 5 \\
\hline $\begin{array}{l}\text { Seler korzeniowy } \\
\text { Celery root }\end{array}$ & 3 & 0 & $<\mathrm{GO}$ & 0,05 \\
\hline $\begin{array}{l}\text { Szałwia } \\
\text { Sage }\end{array}$ & 1 & 0 & $<\mathrm{GO}$ & 5 \\
\hline $\begin{array}{l}\text { Szparagi } \\
\text { Asparagus }\end{array}$ & 3 & 0 & $<\mathrm{GO}$ & 0,5 \\
\hline $\begin{array}{l}\text { Śliwka } \\
\text { Plum }\end{array}$ & 5 & 0 & $<\mathrm{GO}$ & 2 \\
\hline $\begin{array}{l}\text { Truskawka } \\
\text { Strawberry }\end{array}$ & 28 & 2 & 0,$33 ; 2,9$ & 10 \\
\hline $\begin{array}{l}\text { Winogrono } \\
\text { Grape }\end{array}$ & 6 & 1 & 0,06 & 5 \\
\hline $\begin{array}{l}\text { Wiśnia } \\
\text { Cherry }\end{array}$ & 12 & 1 & 0,06 & 2 \\
\hline $\begin{array}{l}\text { Ziemniak } \\
\text { Potato }\end{array}$ & 49 & 0 & $<\mathrm{GO}$ & 0,3 \\
\hline
\end{tabular}

NDP - najwyższy dopuszczalny poziom pozostałości - MRL - Maximum Residue Level

GO - granica oznaczalności - LOQ - Limit of Quantification

analitycznych i jednakowych programach badań. W badaniach krajowych DTC są jedną z najczęściej wykrywanych grup wśród fungicydów (Nowacka i wsp. 2011, 2012). Pozostałości DTC najczęściej wykrywane są w owocach, głównie w porzeczce czarnej (Morzycka i Nowacka 2002; Łozowicka i Kaczyński 2009). Jak podają Morzycka i Nowacka (2002) częstotliwość występowania DTC w latach 1999-2000 na terenie Polski wynosiła od 1,0\% w województwie dolnośląskim do $25,5 \%$ w województwie świętokrzyskim.

Uzyskane wyniki wskazują, że ditiokarbaminianowe środki grzybobójcze są nadal szeroko stosowane w Polsce pomimo dużego asortymentu innych fungicydów dostępnych na rynku. $\mathrm{Z}$ przeprowadzonych badań wynika, iż 
stosowane są one zgodnie $\mathrm{z}$ dobrą praktyką rolniczą. Jednak chcąc zapewnić bezpieczeństwo konsumenta istnieje potrzeba prowadzenia systematycznej kontroli pozostałości ditiokarbaminianów, szczególnie w uprawie owoców.

\section{Wnioski / Conclusions}

1. W badanych próbkach pochodzących $\mathrm{z}$ terenu południowo-wschodniej Polski w latach 2011-2013, pozostałości DTC najczęściej wykrywano w owocach. W warzywach stwierdzono obecność tylko jednej sub- stancji czynnej $\mathrm{w}$ uprawie pomidora spod osłon, natomiast nie stwierdzono pozostałości DTC w uprawach zielarskich.

2. W żadnym przypadku oznaczone w próbkach stężenie ditiokarbaminianów nie przekroczyło NDP.

3. Ze względu na szerokie zastosowanie fungicydów $\mathrm{z}$ grupy DTC oraz bezpieczeństwo konsumentów istnieje potrzeba prowadzenia systematycznej kontroli pozostałości tych związków, szczególnie w uprawach owoców.

\section{Literatura / References}

Belpoggi F., Soffritti M., Guarino M., Lambertini L., Cevolani D., Maltoni C. 2002. Results of long-term experimental studies on the carcinogenicity of ethylene-bis-dithiocarbamate (Mancozeb) in rats. Ann. N Y Acad. Sci. 982: 123-136.

Chmiel Z. 1979. Spektrofotometryczne oznaczanie śladowych pozostałości dwutiokarbaminianów w materiale roślinnym. Chem. Anal. 24: 505-512.

Document SANCO/10684/2011. Method validation and quality control procedures for pesticide residues analysis in food and feed, $40 \mathrm{pp}$.

EPA 2001. The determination of whether dithiocarbamate pesticides share a common mechanism of toxicity. Health Effects Division, Office of Pesticide Programs, US Environmental Protection Agency, Washington DC: 21-29.

Łozowicka B., Kaczyński P. 2009. Pozostałości ditiokarbaminianów w żywności oraz potencjalne ryzyko narażenia konsumentów. Bromat. Chem. Toksykol. 42 (4): 1155-1160.

Morzycka B., Nowacka A. 2002. Monitoring of residues of dithiocarbamate fungicides in Polish crops during 1999-2000. J. Plant Prot. Res. 42 (1): 57-63.

Nowacka A., Gnusowski B., Walorczyk S., Drożdżyński D., Raczkowski M., Hołodyńska A., Frąckowiak D., Wójcik A., Ziółkowski A., Przewoźniak M., Swoboda W., Rzeszutko U., Domańska I., Jurys J., Łozowicka B., Kaczyński P., Rutkowska E., Jankowska M., Hrynko I., Szpyrka E., Rupar J., Rogozińska K., Kurdziel A., Słowik-Borowiec M., Szala J., Szponik M., Michel M. 2012. Pozostałości środków ochrony roślin w płodach rolnych (rok 2011). [Pesticide residues in Polish crops (2011)]. Prog. Plant Prot./Post. Ochr. Roślin 52 (4): 1107-1116.

Nowacka A., Gnusowski B., Walorczyk S., Drożdżyński D., Raczkowski M., Hołodyńska A., Frąckowiak D., Wójcik A., Ziółkowski A., Rzeszutko U., Domańska I., Jurys J., Łozowicka B., Kaczyński P., Rutkowska E., Jankowska M., Hrynko I., Szpyrka E., Rupar J., Rogozińska K., Kurdziel A., Słowik-Borowiec M., Michel M., Kuźmenko A., Szala J. 2011. Pozostałości środków ochrony roślin w płodach rolnych (rok 2010). [Pesticide residues in Polish crops (2010)]. Prog. Plant Prot./Post. Ochr. Roślin 51 (4): $1723-1738$.

PN-EN ISO/IEC 17025. 2005 Ogólne wymagania dotyczące kompetencji laboratoriów badawczych i wzorcujących. PKN, Warszawa, 42 ss.

Rozporządzenie Ministra Zdrowia z dnia 17 października 2007 r. w sprawie pobierania próbek żywności w celu oznaczania poziomów pozostałości pestycydów. 2007. Dz. U. nr 207, poz. 1502.

Rozporządzenie 396/2005 Parlamentu Europejskiego i Rady z dnia 23 lutego 2005 r. w sprawie najwyższych dopuszczalnych poziomów pozostałości pestycydów w żywności i paszy pochodzenia roślinnego i zwierzęcego oraz na ich powierzchni, zmieniające dyrektywę Rady 91/414/EWG (Dz. Urz. L 70 z 16.03.2005 r. z późn. zm.), 16 ss.

Różański L. 1992. Przemiany pestycydów w organizmach żywych i środowisku. PWRiL, Warszawa, 274 ss.

Sadło S., Szpyrka E., Rogozińska K., Rupar J. 2003. Oznaczanie pozostałości ditiokarbaminianów w owocach i warzywach na poziomie $0,01 \mathrm{mg} / \mathrm{kg}$. [Determination of dithiocarbamate residues in fruits and vegetables at the level of $0.01 \mathrm{mg} / \mathrm{kg}$ ]. Prog. Plant Prot./Post. Ochr. Roślin 43 (2): 895-897.

WHO 1994. Pesticide Residues in Food - 1993. Evaluations. Part II - Toxicology. International Programme on Chemical Safety: 855-874. 